\title{
Laboratory Markers and Mortality in Novel Coronavirus Disease 2019 (COVID-19): A Systematic Review and Meta- Analysis
}

\author{
Joshua Davis ${ }^{1 *}$, Shane Geffe ${ }^{2}$, Gina Hana ${ }^{3}$ and Connor Talbott \\ ${ }^{1}$ Emergency Medicine Physician at Vituity, Wichita, KS, USA \\ ${ }^{2}$ College of Medicine/Lee Health, Florida State University, Fort Meyers, FI, USA \\ ${ }^{3}$ School of Medicine, University of California Irvine Irvine, CA, USA \\ ${ }^{4}$ Reno School of Medicine, University of Nevada, Reno, NV, USA
}

\begin{abstract}
Background: Novel coronavirus disease 2019 (COVID-19) is associated with high mortality. Many laboratory values have been suggested to predict patients at risk for a poor outcome in COVID-19. The objective of this project was to systematically review and meta-analyze all laboratory markers associated with prognosis of mortality in patients with COVID-19.

Methods: We searched OVID Medline, SCOPUS, MedRxIv, preprints.org, and Centers for Disease Control databases from November 2019 to April 10, 2020 for articles on laboratory values and mortality in COVID-19 and updated the search July 20, 2020. Teams of 2 independent reviewers reviewed titles and abstracts for studies that reported mortality and laboratory values and subsequently abstracted relevant data.

Results: Our initial search identified 6,973 articles and a total of 96 articles (30 articles from first search and 66 from updated search) on 72 laboratory values were included. Many laboratory values were associated with mortality, but those most associated with mortality included lymphopenia (OR $0.30,95 \% \mathrm{Cl} 0.24-0.36$ ), thrombocytopenia (OR 0.46, $95 \% \mathrm{Cl} 0.35-0.60)$, elevated lactate dehydrogenase (OR 7.32, 95\% Cl 5.19-10.33), and ferritinemia (OR 5.19, 95\% Cl 3.078.62). All cardiac markers were associated with mortality, with troponin being the least associated. A low $\mathrm{PaO} 2: \mathrm{FiO} 2$ ratio was also associated with mortality (OR $0.13,95 \% \mathrm{Cl}-0.06-0.28)$. Heterogeneity was high and risk of bias was moderate.

Conclusions: This meta-analysis identified many laboratory abnormalities associated with mortality in COVID-19, though was limited by heterogeneity. Laboratory markers previously identified as associated with a poor prognosis in COVID-19 were confirmed to be those most associated with mortality in this large meta-analysis.
\end{abstract}

Keywords

Coronavirus, SARS, COVID-19, Mortality, Systematic Review, Laboratory

\section{Introduction}

Novel coronavirus disease 2019 (COVID-19) has caused over a million international deaths and overwhelmed healthcare systems internationally: Wuhan, China; Lombardy, Italy; and New York City, New York. This disease has led to overall mortality rates from 1-6\%, [1-3] with the subset of patients who require critical care or intubation having mortality as high as $50-80 \%[4,5]$.

The vast majority of patients will be asymptomatic or minimally symptomatic [6] and can be treated at home. However, a small percentage of patients will require hospitalization for aggressive supportive care - supplemental oxygen, intubation, and sometimes cardiac support [7]. Those at most risk for severe outcomes appear to be the obese, [8] the elderly, [3] and those with prior heart or lung disease [9]. Given the stretch on limited resources, predicting those at risk of de-

*Corresponding author: Joshua Davis, MD, Emergency Medicine Physician at Vituity, 929 N. St. Francis St. Wichita, KS 67214, USA

Accepted: December 28, 2020

Published online: December 30, 2020

Citation: Davis J, Geffe S, Hana G, et al. (2020) Laboratory Markers and Mortality in Novel Coronavirus Disease 2019 (COVID-19): A Systematic Review and Meta-Analysis. Sch J Emerg Med Crit Care 4(1):106-120 
terioration or mortality would be helpful to clinicians when making disposition or treatment decisions.

Several laboratory values have been proposed to predict severe illness. These include nonspecific inflammatory markers (C-reactive protein and ferritin), [10] liver enzymes (AST, ALT, LDH), [11] and blood cell counts (platelets, white blood cells, and lymphocytes) [10]. D-Dimer has been highly associated with mortality, with the newest theories recognizing that this may be due to risk of thrombotic complications, and not just inflammation alone $[12,13]$. As with many other diseases, troponin elevations, too, have been associated with mortality $[14,15]$.

Given the reports of associations of these laboratory values and prognosis, we sought to do a systematic review and meta-analysis of laboratory values associated with mortality in adult patients with COVID-19.

\section{Methods}

This study was conducted in accordance with Preferred Reporting in Systematic Review and Meta-Analysis Guidelines (PRISMA) [16]. The PRISMA Checklist is available in Supplement 1 and the research protocol is available from the authors upon request. This study had no human subjects and was, therefore, exempt from Institutional Review Board Review.

\section{Search strategy and study selection}

We searched OVID Medline, SCOPUS, MedRxIV, preprints. org, and Centers for Disease Control (CDC) databases from November 2019 to April 10, 2020. The search used keyword terms for "COVID-19", "SARS", or "coronavirus". The CDC database was already compiled and was only filtered for English articles. Per PRISMA guidelines, 1 sample search strategy, in detail, is available in the Supplement 2. A complete search strategy is available from the authors upon reasonable request. The search was updated on July 20, 2020 with a focused search in PubMed and MedRxIV, using the laboratory values found in the initial search. These 2 sources were chosen because they could conduct a focused search that was also date limited to the month level and included one published and one unpublished source. An example of the updated search strategy is also available in Supplement 2. We reviewed citations from included articles, review articles, and suggestions from select content experts to find relevant articles that may have been missed. We also contacted authors of studies that appeared to have underlying data that would answer the research question to ask for additional data. Titles and abstracts from these search methods were screened independently by 3 trained reviewers (CT, SG, GH). If any reviewer thought an article was potentially relevant, a full text copy of the article was ordered and again reviewed for inclusion by these 3 authors.

Inclusion criteria were any research study type that evaluated human adult patients with COVID-19 and any laboratory value associated with mortality. Exclusion criteria included opinions (i.e. editorials, letters without data, etc.), abstracts, non-English papers, studies only on children, studies with <
10 participants, or studies with not enough data to address the research question. We did include preprint articles that are not yet peer reviewed. We planned to contact authors for updated data if data was incomplete. After full text review for inclusion, all authors independently identified articles for exclusion and any discrepancies were resolved with a consensus meeting among all 4 authors (JD, CT, SG, GH).

\section{Data extraction and data synthesis}

After title and abstract selection, a standardized abstraction form was developed by all of the authors. Two of three authors (CT, SG, GH) abstracted data from the studies and compared their results for discrepancies. These were resolved by consensus among all authors. Data included authors, publication year, population, setting, intervention, mortality, and other outcomes.

\section{Risk of bias}

Risk of bias within a study was assessed using the Quality in Prognostic Studies (QUIPS) tool. This was assessed by one author (JD) and verified by one other un-blinded author. Funnel plot analyses for each laboratory value was conducted for publication bias and heterogeneity was assessed using $\mathrm{I}^{2}$.

\section{Statistical analysis}

Statistical analysis was conducted in RevMansoftware, version 5 (Review Manager (RevMan) [Computer program]. Version 5.4, The Cochrane Collaboration, 2020). A random effects model and inverse variance weighting was used in all analyses. All laboratory values with more than 2 studies were included in the meta-analysis. All of these were included in a standardized mean difference analysis. Studies who reported averages (either mean or median) were also included in an absolute mean difference analysis for laboratory values that were conducted on the same scale. Laboratory values were transformed to International System units when able, but laboratory values on different scales (e.g., C-reactive protein), where different assays may affect results (e.g., D-Dimer), or similar lab tests with different implications and measures (troponin I and troponin T) were not combined for absolute mean difference analysis and only included in a standardized mean difference analysis. Authors of studies that did not report averages were contacted to request this data. Studies that reported median data were transformed using the method recommended by Cochrane [18] and modified for low sample sizes when applicable using the method described by Wan, et al. [19] or Hozo, et al. [20] as applicable based on available data. Data for odds ratios (ORs), hazard ratios, and relative risk were transformed to standardized mean differences and associated standard errors using the method described by Chinn, et al. [21]. Unadjusted/unweighted ratios were preferred when available. In studies with a group with no patients, a dummy variable of 0.5 was used in calculation of odds ratio/standardized mean difference, and in studies with a group with no variance, the average of the standard deviations from all other studies on that laboratory test or the average value itself was used, whichever was lower. If there was no difference and no variance reported, a standard error of 0.01 was used. Studies that reported multiple 


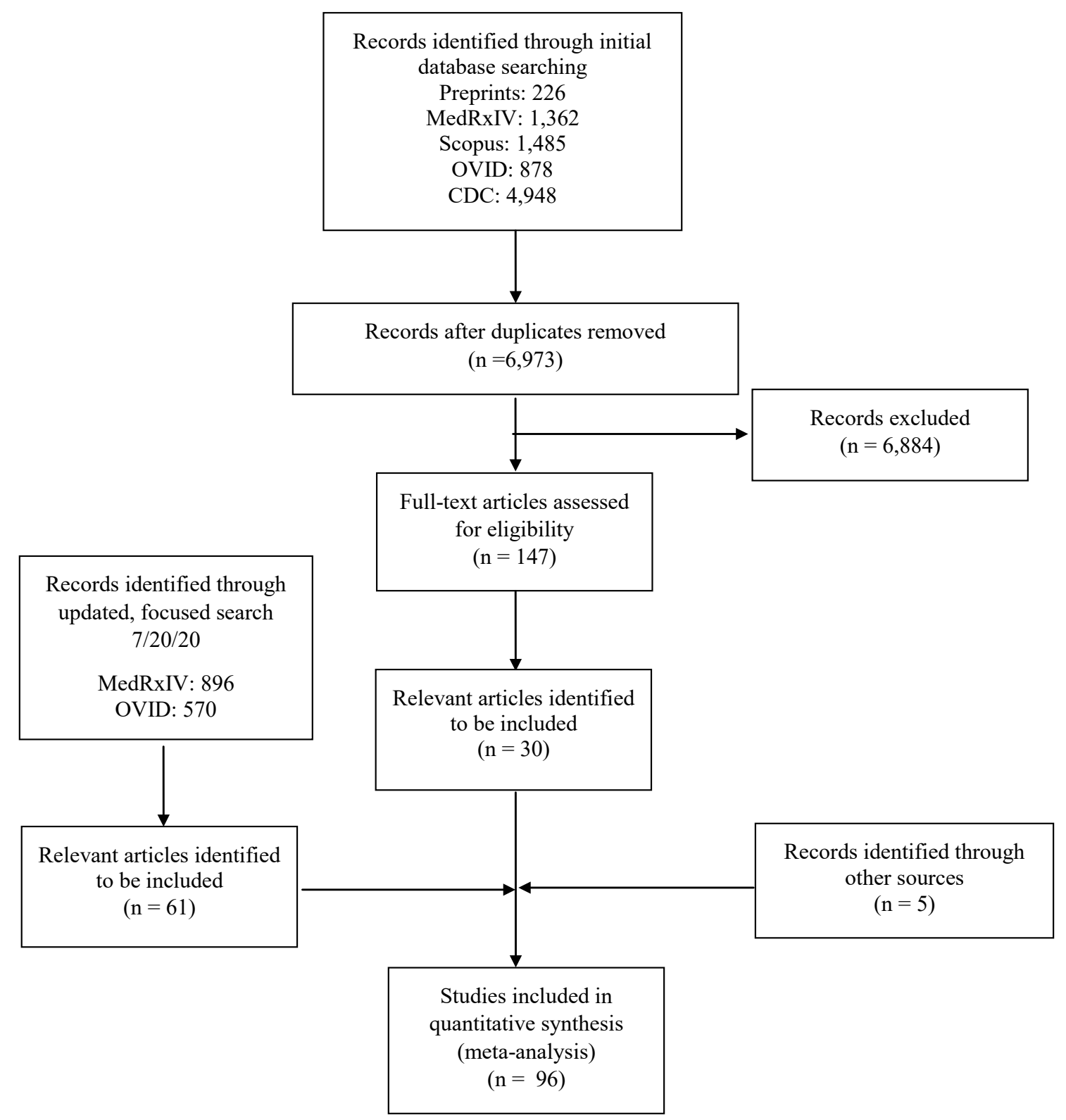

Figure 1: Flow diagram of studies included in a meta-analysis of laboratory values and mortality in COVID-19.

Table 1: Summary of characteristics of 91 studies included in a metaanalysis of laboratory values and mortality in COVID-19.

\begin{tabular}{|c|c|c|}
\hline & $\mathrm{N}$ & $\%$ \\
\hline \multicolumn{3}{|l|}{ Year } \\
\hline 2020 & 96 & $100 \%$ \\
\hline \multicolumn{3}{|l|}{ Country } \\
\hline China & 67 & $70 \%$ \\
\hline United States & 10 & $10 \%$ \\
\hline Italy & 8 & $8 \%$ \\
\hline Spain & 3 & $3 \%$ \\
\hline United Kingdom & 3 & $3 \%$ \\
\hline Iran & 1 & $1 \%$ \\
\hline Canada & 1 & $1 \%$ \\
\hline International & 1 & $1 \%$ \\
\hline
\end{tabular}

\begin{tabular}{|l|l|l|}
\hline Mexico & 1 & $1 \%$ \\
\hline Belgium & 1 & $1 \%$ \\
\hline Study type & \multicolumn{2}{l|}{} \\
\hline Retrospective cohort & 59 & $61 \%$ \\
\hline Case control & 22 & $23 \%$ \\
\hline Prospective cohort & 14 & $15 \%$ \\
\hline Ambispective cohort & 1 & $1 \%$ \\
\hline Patient type & & \\
\hline Inpatient & 69 & $72 \%$ \\
\hline ICU & 12 & $13 \%$ \\
\hline Inpatient/ICU & 9 & $9 \%$ \\
\hline Inpatient/Outpatient & 1 & $1 \%$ \\
\hline Unclear & 3 & $3 \%$ \\
\hline
\end{tabular}

COVID-19: Novel coronavirus disease 2019; ICU: Intensive care unit. 
different patient cohorts were included in separate analyses, but studies that had one cohort but separated "control" outcomes (i.e. severe vs. non-severe illness) were combined into one control group (survived). Studies that reported different analyses of the same outcome were only included once, with the preference for average (mean/median) data. Preprint articles that were subsequently published were only included once. Statistical significance was set at an alpha of 0.001 to account for multiple analyses.

\section{Results}

Our initial search identified 6,973 unique articles. 147 of these were identified for full text review, and 30 were deemed to meet all inclusion and no exclusion criteria (Figure 1). In the updated search, 61 new articles were identified (896 from medRxIV and 570 from PubMed), and 52 were included (18 from medRxIV and 34 from PubMed). Two studies in the initial search had since been published from a preprint form and these published versions were used. A total of 105 authors were contacted ( 90 for primary data and 15 for clarification of printed data). Thirteen of these authors responded (12.9\%) and 10 (9.9\%) of those provided new data. A total of 96 unique studies $[11,12,14,15,22-113]$ with 30,985 patients and 72 different laboratory values were included. A summary of the characteristics of the included studies is in Table 1 and details of each study are available in Supplement 3.

The summary of the standardized mean difference analysis is available in Table 2. A summary of the results for the absolute mean difference analysis is available in Table 3. A forest plot and funnel plot for each laboratory value is available in Supplement 4, Supplement 5 and Supplement 6.

\section{Hematologic}

The most predictive complete blood cell count test was neutrophil percent (OR 26.47, 95\% Cl 5.68-121.09), though this was limited by a small number of studies and a wide confidence interval. Nonetheless, absolute neutrophil count (OR $4.66,95 \% \mathrm{Cl} 3.30-6.45)$ and neutrophil to lymphocyte ratio (OR 3.36, 95\% Cl 1.60-6.57) were also the next most significant positive associations with mortality, and a low absolute lymphocyte count (OR $0.30,95 \% \mathrm{Cl} 0.24-0.36)$ and lymphocyte percent (OR $0.05,95 \% \mathrm{Cl} 0.02-0.11$ ) were the most significant negative correlations, as was thrombocytopenia (OR $0.46,95 \% \mathrm{Cl} 0.35-0.60)$. There was a moderate association with leukocytosis and mortality, as well (OR $3.68,95 \% \mathrm{Cl}$ 2.914.74).

The absolute differences for white blood cell count $(2.38$ $10 \%$ L, 95\% Cl 1.97-2.79), absolute neutrophil count (2.61 $10 \% / \mathrm{L}, 95 \% \mathrm{Cl} 2.04-3.18)$, and absolute lymphocyte count $(-0.3410 \% / \mathrm{L}, 95 \% \mathrm{Cl}-0.28--0.4)$ were modest. The absolute difference in neutrophil to lymphocyte ratio $(4.04,95 \% \mathrm{Cl}$ 1.59-6.48) and neutrophil $(19.28 \%, 95 \% \mathrm{Cl} 12.33-26.22)$ and lymphocyte percent $(-15.21 \%, 95 \% \mathrm{Cl}-12.33-18.08)$ were more apparent. Thrombocytopenia also seemed to have a significant absolute difference $\left(-39.8510^{9} / \mathrm{L}, 95 \% \mathrm{Cl}-27.65-\right.$ -52.06).

Almost all lymphocyte subsets were negatively correlated

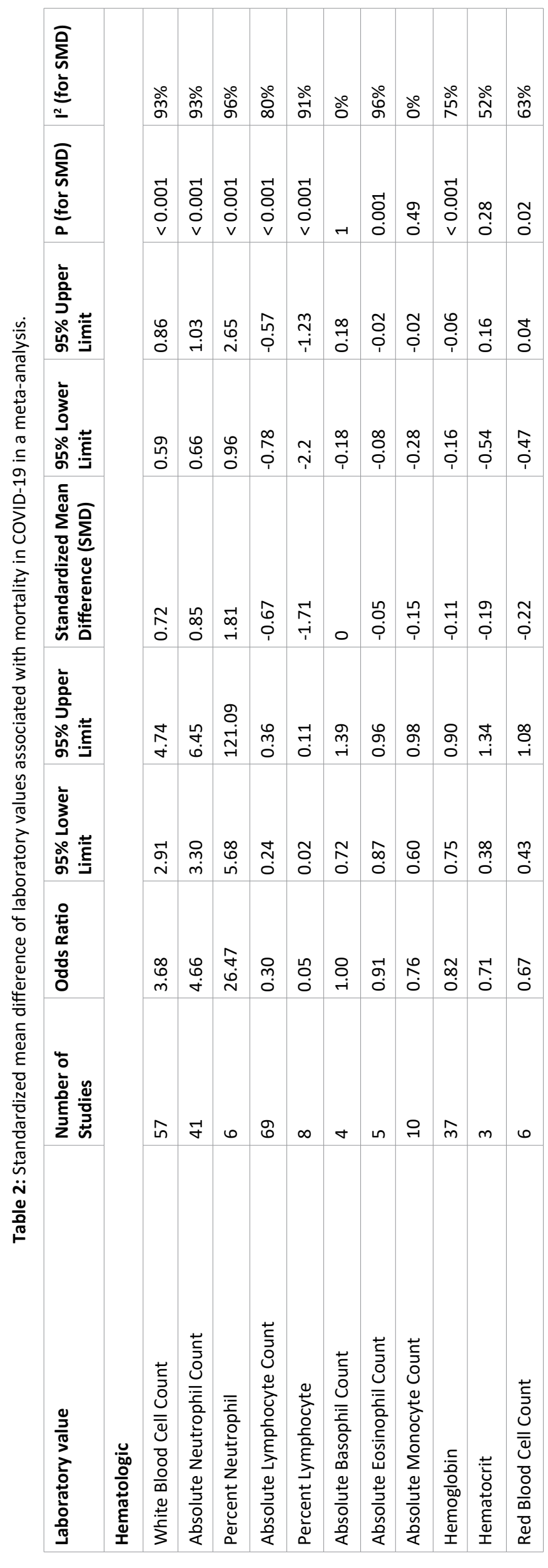




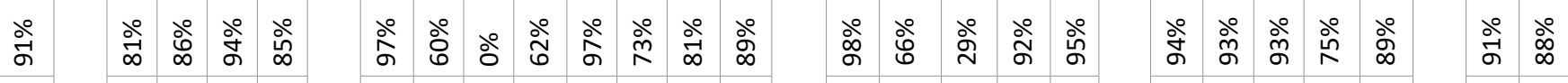

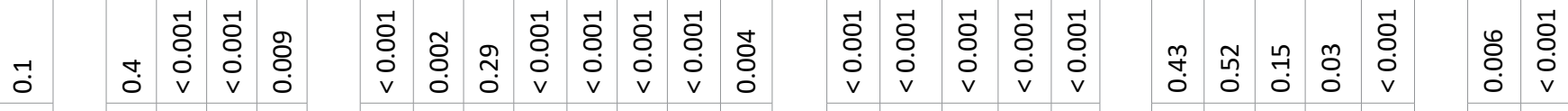

票

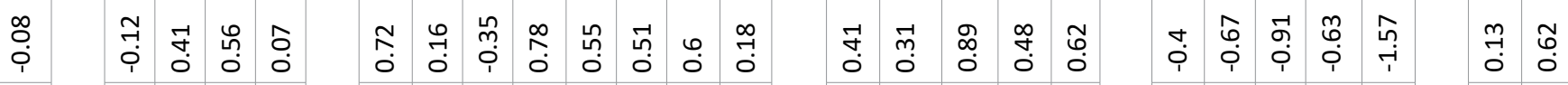

₹ f

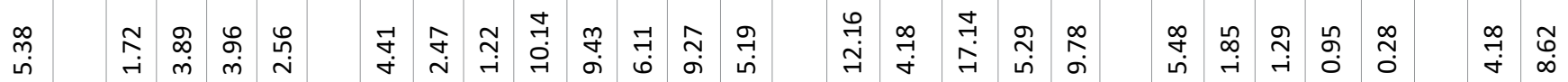

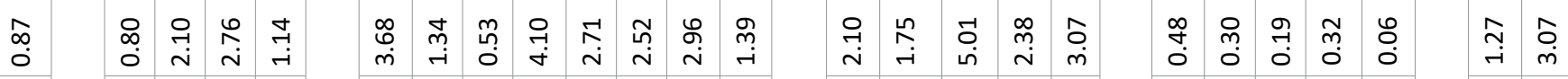

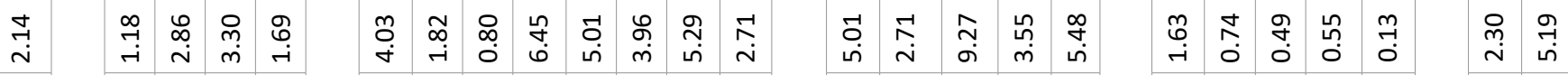

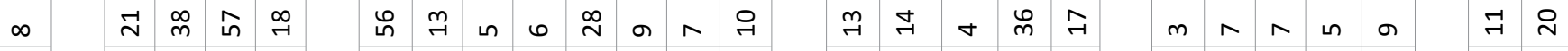

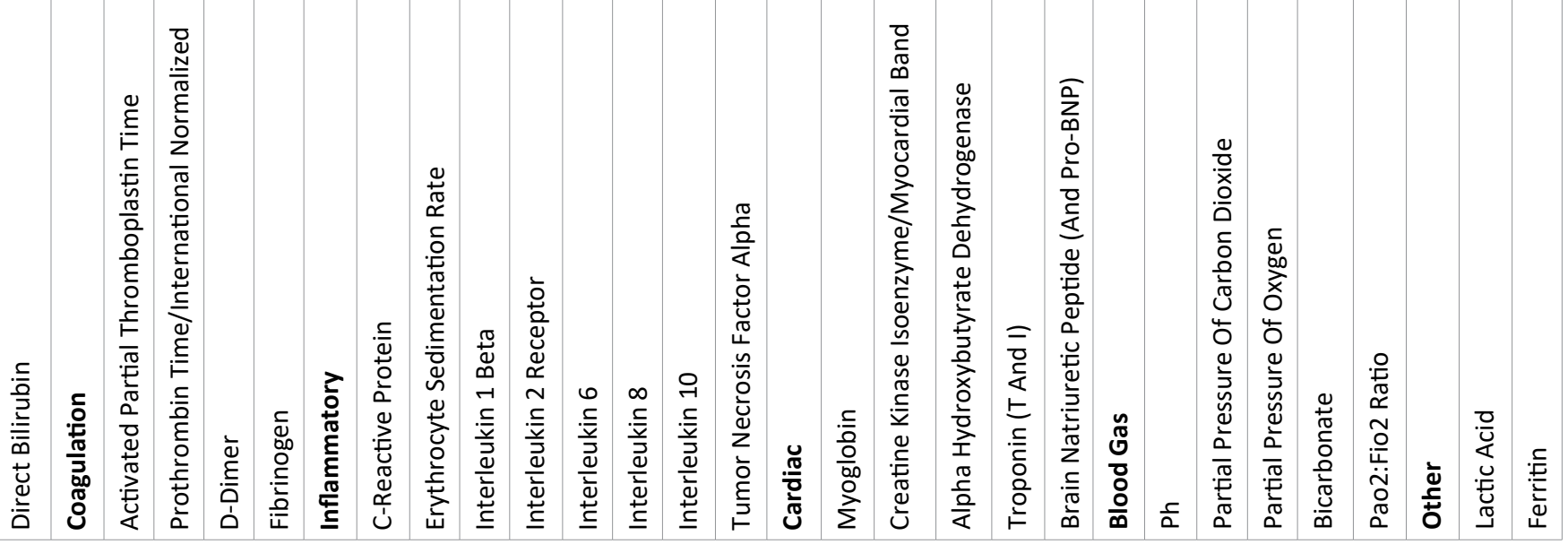




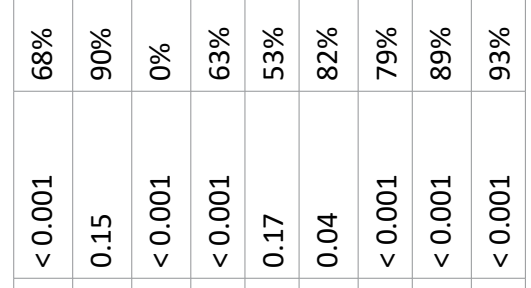

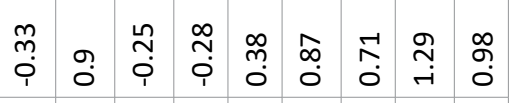

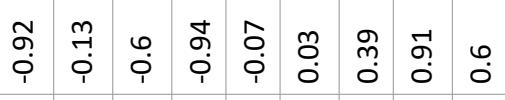

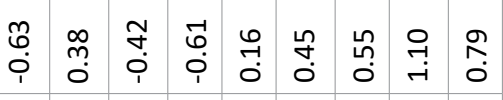

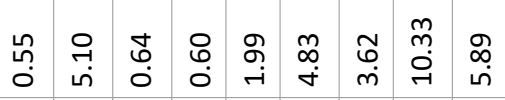

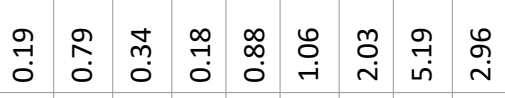

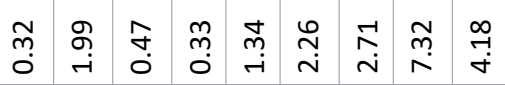

0 in in in in $6 \stackrel{\infty}{\sim}$ \& $\stackrel{\infty}{m}$

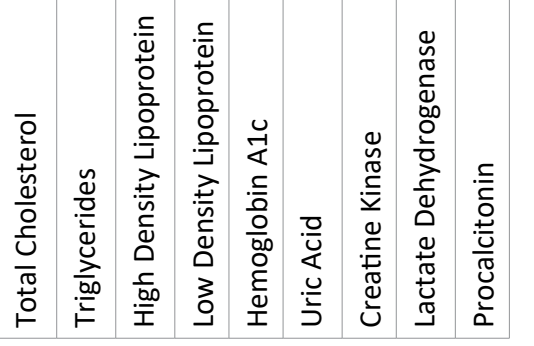

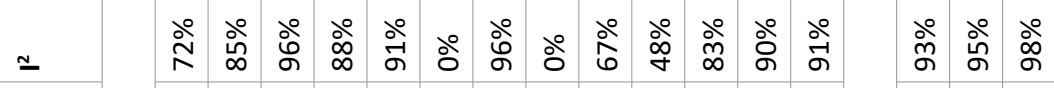

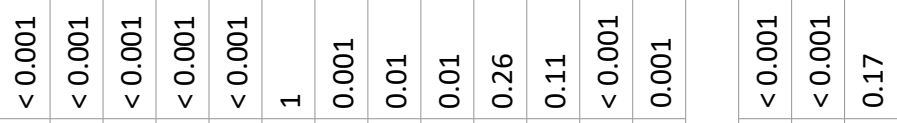

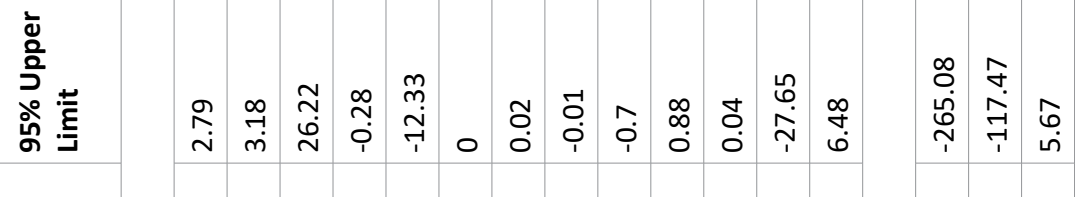

离

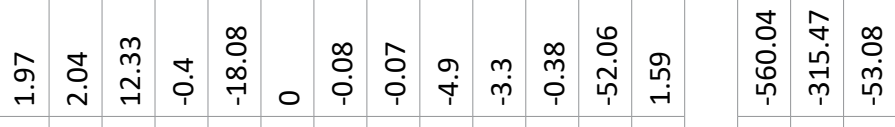

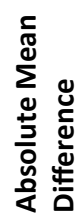

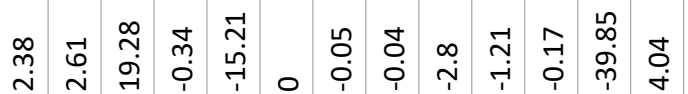

究

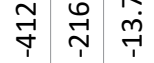

는

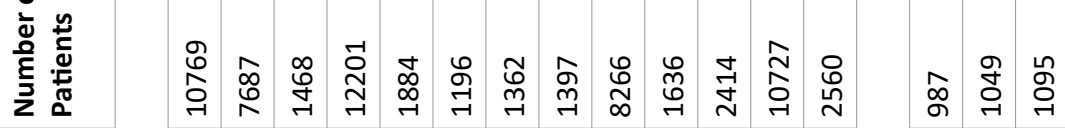

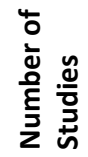

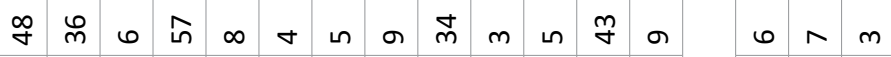

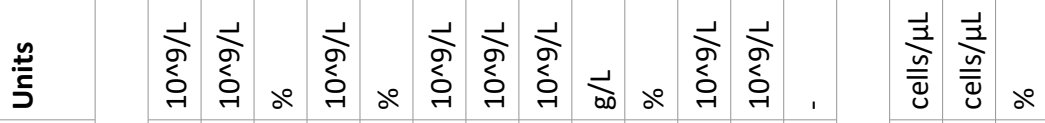

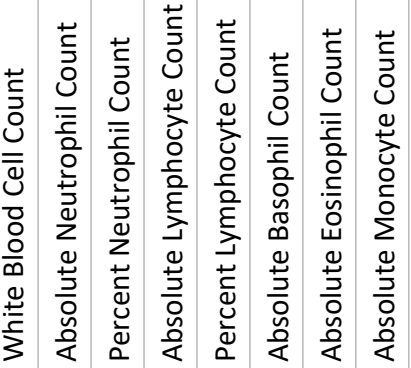

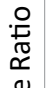

苛

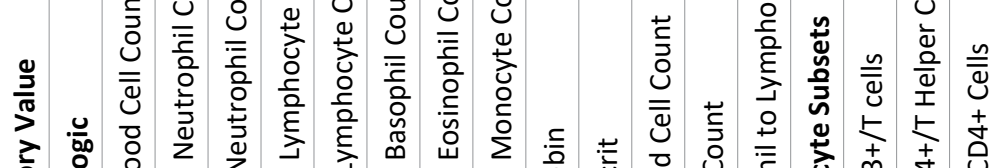

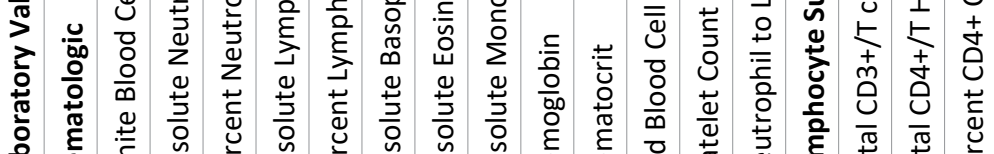

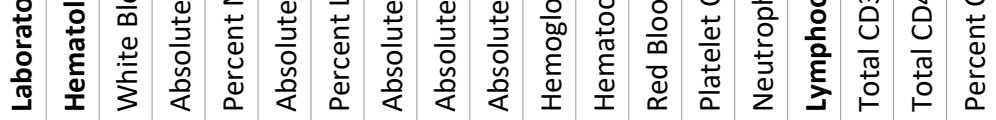




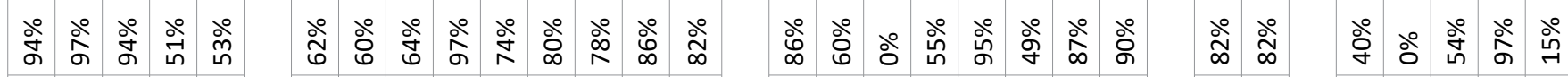

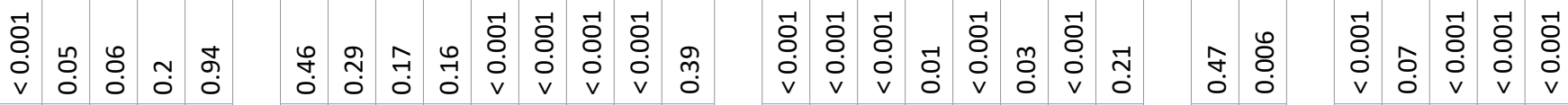

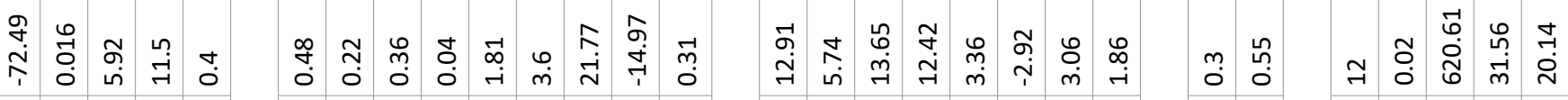

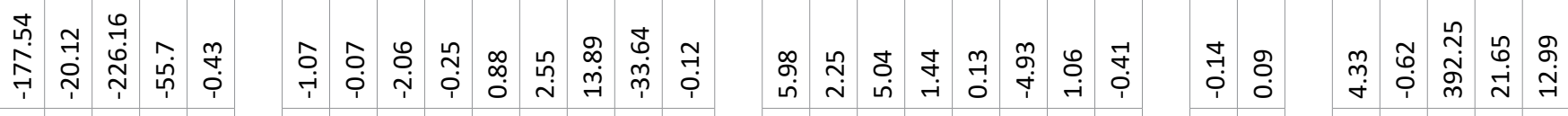

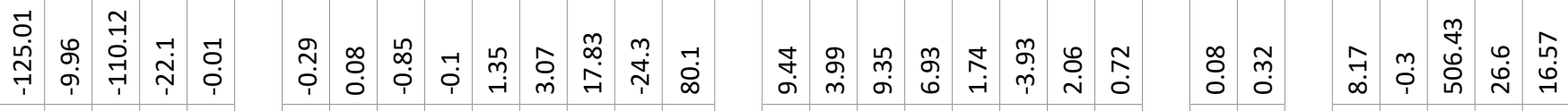

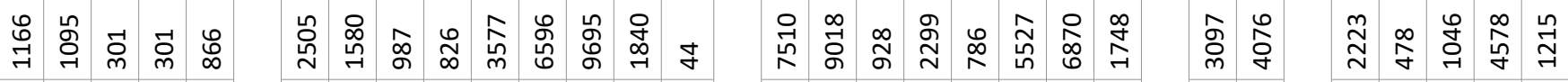

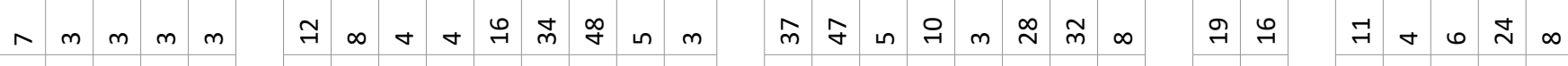

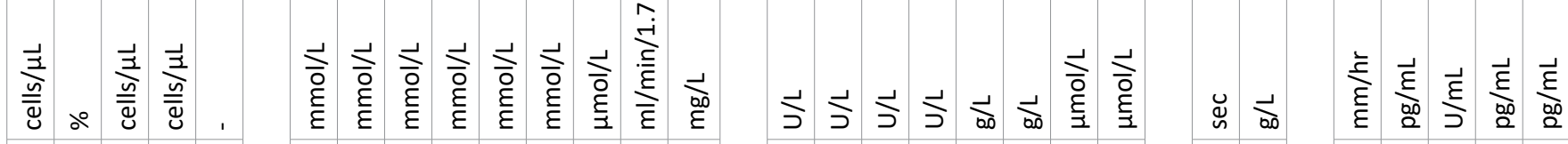

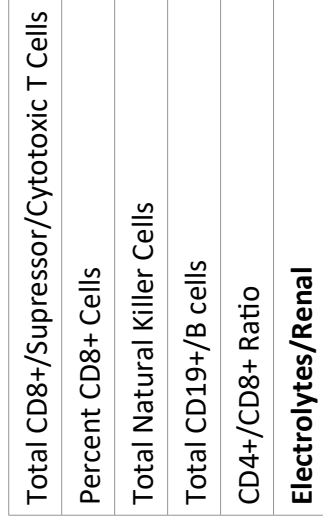




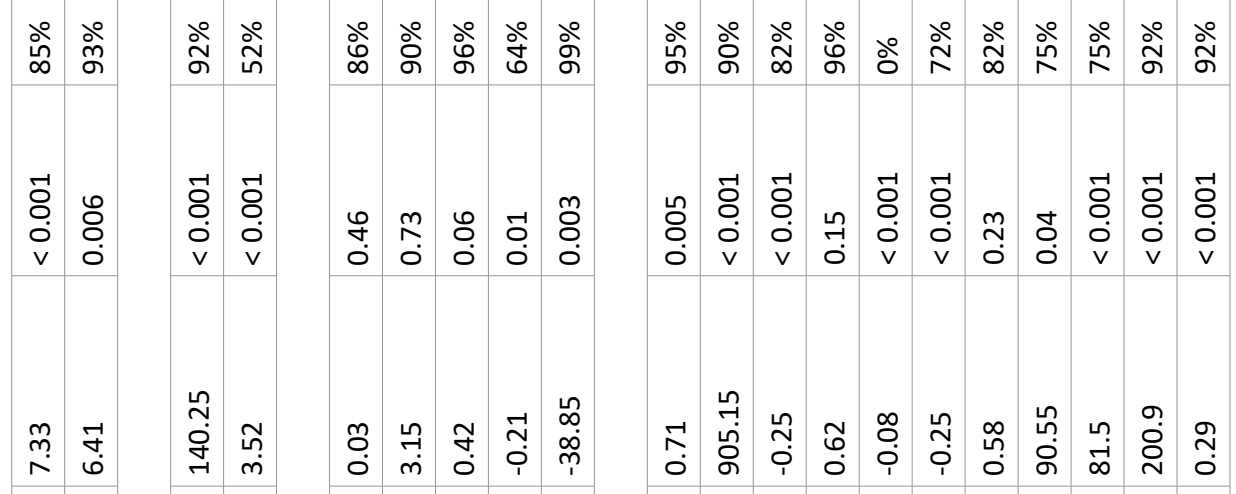

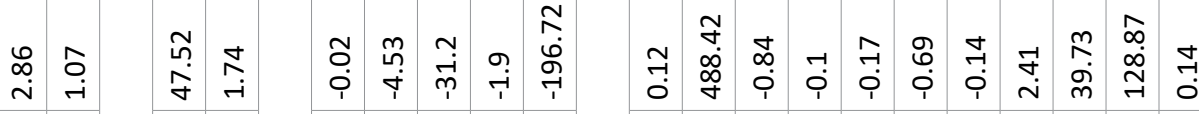

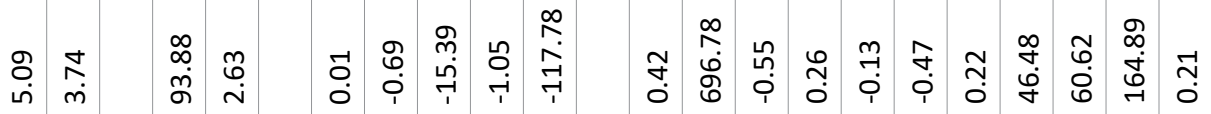

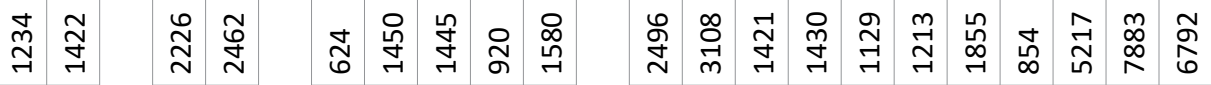

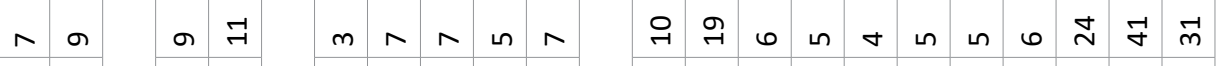

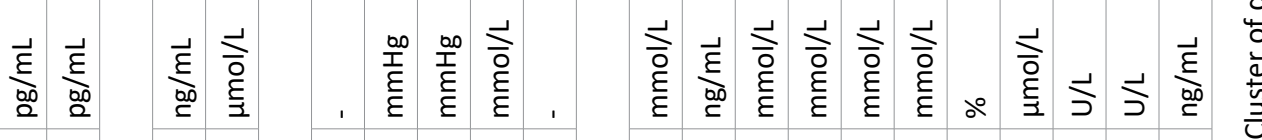

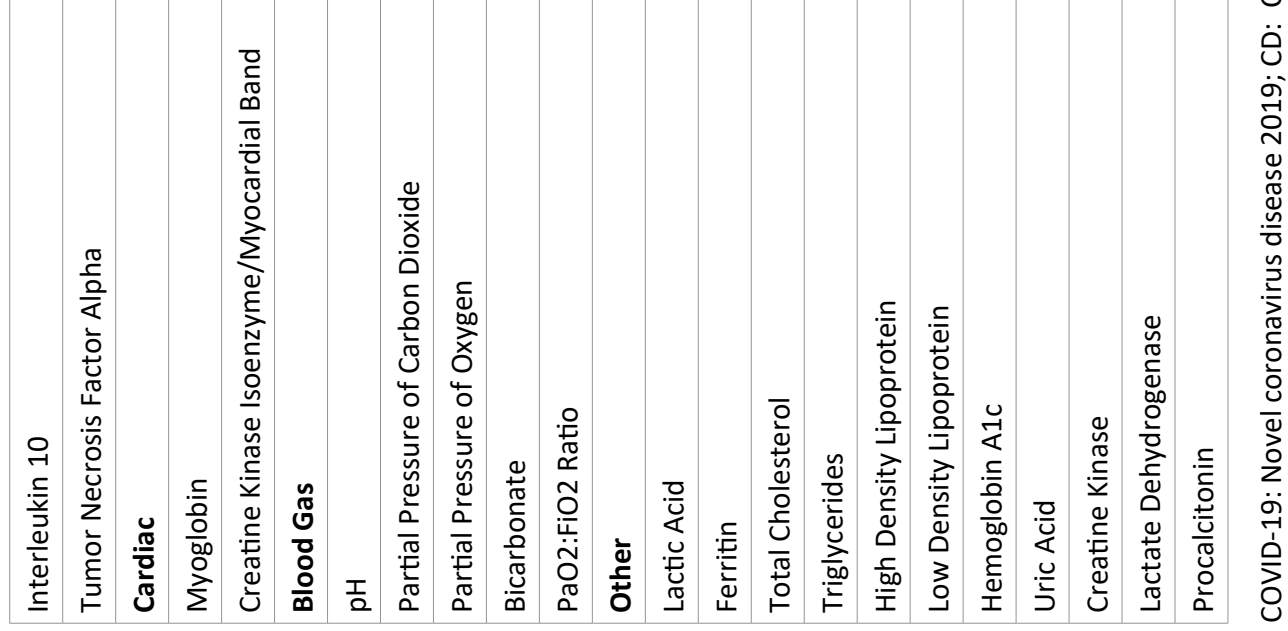


Citation: Davis J, Geffe S, Hana G, et al. (2020) Laboratory Markers and Mortality in Novel Coronavirus Disease 2019 (COVID-19): A Systematic Review and Meta-Analysis. Sch J Emerg Med Crit Care 4(1):106-120

with mortality, except there was no significant association between CD19+/B cells and CD4+ to CD8+ ratio.

\section{Electrolytes, renal, and liver function}

Among electrolytes and renal function, only glucose (OR 2.66, 95\% Cl 1.75-4.03), blood urea nitrogen (BUN, OR 7.06, $95 \% \mathrm{Cl} 4.33-11.51$ ), creatinine (OR 2.43, 95\% Cl 2.22-2.66) and low glomerular filtration rate (GFR, OR 0.27, 95\% Cl 0.11-0.62) were significant. Nearly all liver function tests (aspartate aminotransferase (AST), alanine aminotransferase (ALT), alkaline phosphatase (ALP), gamma glutamyl transpeptidase (GGT), total bilirubin) were significantly associated with mortality, with AST being most significant (OR 2.61, 95\% Cl 1.92-3.55) and more significant than ALT (OR 1.22, 95\% Cl 1.14-1.29). A low albumin was also significantly associated with mortality (OR 0.24, 95\% Cl 0.17-0.33). Globulin and direct bilirubin had no significant association with morality, but both were limited by a small number of studies.

The absolute difference in creatinine $(17.83 \mu \mathrm{mol} / \mathrm{L}, 95 \%$ $\mathrm{Cl} 13.89-21.77)$ and GFR $\left(-24.3 \mathrm{ml} / \mathrm{min} / 1.7 \mathrm{~m}^{2}, 95 \% \mathrm{Cl}-14.97-\right.$ -33.64) were most significant. AST $(9.44 \mathrm{U} / \mathrm{L}, 95 \% \mathrm{Cl} 5.98$ 12.91) and ALP (9.35 U/L, 95\% $\mathrm{Cl} 5.04-13.65)$ were the most significant absolute liver functions.

\section{Coagulation}

D-Dimer is the most significant coagulation parameter associated with mortality (OR 3.30, 95\% Cl 2.76-3.96), followed by prothrombin time/International Normalized Ratio (PT/ INR, OR 2.86, 95\% Cl 2.10-3.89). Because these parameters are laboratory specific, an absolute mean difference was not calculated for them.

\section{Inflammatory}

Aside from interleukin measures, C-reactive protein (CRP) is the most significant inflammatory marker associated with morality (OR 4.03, 95\% Cl 3.68-4.41), and much more so than erythrocyte sedimentation rate (ESR, OR $1.82,95 \% \mathrm{Cl} 1.34$ 2.47). All of the interleukin tests studied except interleukin 1 beta were significantly associated with mortality. Among the interleukin tests, interleukin 2 receptor (OR 6.45, 95\% Cl 4.1010.14), interleukin 10 (OR 5.39, 95\% Cl 2.96-9.27), and interleukin 6 (OR 5.01, 95\% Cl 2.71-9.43) were most significant.

An absolute mean difference of CRP was not calculated due to its dependence on lab variability. The absolute mean difference in interleukin 2 receptor was most apparent (506.43 U/mL, 95\% Cl 392.25-620.61).

\section{Cardiac}

All cardiac markers (myoglobin, creatine kinase-myocardial band (CK-MB), alpha hydroxybutyrate dehydrogenase, troponin, and brain natriuretic peptide (BNP and pro-BNP)) were significantly associated with mortality, with alpha hydroxybutyrate dehydrogenase (OR 9.27, 95\% Cl 5.01-17.14), BNP (OR 5.48, 95\% Cl 3.07-9.78), and myoglobin (OR 5.01, 95\% Cl 2.10-12.16) the most significantly associated. Troponin and BNP were not analyzed for absolute mean difference due to their various laboratory tests (i.e. troponin I and troponin $T$ or BNP and pro-BNP) and different cutoffs and interpretation. Myoglobin (93.88 ng/mL, 95\% Cl 47.52-140.25) and CK-MB (2.63 $\mu \mathrm{mol} / \mathrm{L}, 95 \% \mathrm{Cl}$ 1.74-3.52) were both significantly associated with mortality in the absolute mean difference analysis as well.

\section{Blood Gas}

In the analysis of blood gas level, only $\mathrm{PaO} 2: \mathrm{FiO} 2$ ration ( $\mathrm{P} / \mathrm{F}$ ratio) was significant (OR $0.13,95 \% \mathrm{Cl}-0.06-0.28$ ) with an absolute mean difference of -117.78 ( $95 \% \mathrm{Cl}-38.85$ - -196.72).

\section{Other}

Among the other tests studied, lactate dehydrogenase (OR 7.32, 95\% Cl 5.19-10.33) and ferritin (OR 5.19, 95\% Cl 3.07-8.62) were most significant. Lactic acid, triglycerides, hemoglobin A1c, and uric acid were not significant. Lower levels of total cholesterol (OR $0.32,95 \% \mathrm{Cl} 0.19-0.55)$, high density lipoprotein (OR $0.47,95 \% \mathrm{Cl} 0.34-0.64$ ), and low density lipoprotein (OR 0.33, 95\% Cl 0.18-0.60) were associated with increased mortality. Elevated creatine kinase (CK, OR 2.71, 95\% $\mathrm{Cl}$ 2.03-3.62) and procalcitonin (OR 4.18, 95\% Cl 2.96-5.89) were also significantly associated with mortality, but less so.

Absolute mean differences in ferritin $(696.78 \mathrm{ng} / \mathrm{mL}, 95 \%$ Cl 488.42-905.15), LDH (164.89 U/L, 95\% Cl 128.87-200.9), and $\mathrm{CK}(60.62 \mathrm{U} / \mathrm{L}, 95 \% \mathrm{Cl} 39.73-81.5)$ were the largest. Other values were statistically significant but much smaller.

\section{Risk of bias}

The risk of bias within studies was low in $27 \%(n=26)$, moderate in $63 \%(n=60)$, and high in $11 \%(n=10)$ of studies. The most common reason for high risk of bias was selective patient population. The most common reason for moderate risk of bias was either not accounting for patients still hospitalized or unclear reporting of the timing of either the laboratory value or the outcome (mortality). Overall heterogeneity was moderate to high with $58 \%$ (38/65) of laboratory values in the absolute mean difference analysis and 60\% (43/72) in the standardized mean difference with $\mathrm{I}^{2}$ values $>80 \%$. Funnel plot analyses showed most values with a low risk of publication bias.

\section{Discussion}

This systematic review and meta-analysis identified many laboratory abnormalities associated with mortality in COVID-19, but was limited by heterogeneity and risk of bias. Laboratory tests that have been previously identified to have prognostic and diagnostic accuracy seem to be the most associated with mortality. This includes lymphopenia, thrombocytopenia, leukocytosis, elevated liver enzymes, elevated LDH, elevated cardiac enzymes, and elevated ferritin [10-15,114].

In light of the pandemic nature of COVID-19, the ability to accurately identify patients at risk for poor outcome is paramount. Most patients with COVID-19 do not die from it. Given that this disease has placed a strain on healthcare resources in many locations and will continue to potentially do so, identification of patients who need some of these precious resources, like hospitalization or ICU care, will help in fair al- 
location. When effective targeted treatments are identified, these prognostic values may also help identify patients who are most likely to benefit from these therapies.

In regards to specific laboratory values, the combination of neutrophilia and lymphopenia has been combined into a relatively new value called the neutrophil to lymphocyte ratio (NLR). This has been studied in several infectious and inflammatory processes, like bacteremia, [115] pancreatitis, $[116,117]$ and pulmonary embolism [118], and has shown some diagnostic and prognostic value. It appears to be significantly associated with mortality in our meta-analysis.

All cardiac biomarkers studied were significantly associated with mortality. This is not surprising, as the risk of cardiac involvement in COVID-19 has been well studied and has been previously associated with mortality [119]. COVID-19, too, has been reported to be associated with fatal myocarditis [120]. Interestingly, troponin, which is one of the more common cardiac biomarkers evaluated, is one of the least significant markers compared to other values like myoglobin and alpha hydroxybutyrate dehydrogenase.

Only the $\mathrm{P} / \mathrm{F}$ ratio was significant when examining blood gas levels. One of the hallmarks of COVID-19 is a ARDS-like illness. P/F has been well studied in ARDS and has been shown to be associated with mortality, so its association with mortality in COVID-19 should be no surprise. More interesting, though, $\mathrm{pH}$ and $\mathrm{pO}_{2}$ have no significance and lactic acid, interestingly, has only minimal significance.

When examining liver enzymes, AST, ALT, ALP, and GGT all have significant association with mortality. However, AST appears to be much more associated than ALT. This, in addition to the GGT elevation, has been described in the prior SARS outbreak [121], but is not typical of other viral hepatitis entities [122], like hepatitis B or C. It is more commonly seen in ischemic or congestive hepatopathy [123]. Therefore, direct viral injury may not be the only pathophysiology of liver injury in COVID-19 [124,125].

Nearly all markers of inflammation appear to be significantly associated with mortality in COVID-19, including tumor necrosis factor alpha and several interleukin levels. CRP appears to be the most significant inflammatory marker that is commonly available in clinical practice. Several other markers that have significant association with inflammation are also elevated, like D-Dimer, ferritin, and LDH. The pathophysiology of these values is poorly understood. D-Dimer has been hypothesized to be elevated not only due to inflammation but also due to a hypercoagulable state. However, recent research has shown that COVID-19 may not, in fact, be a hypercoagulable state [126] despite initial anecdotal reports and observations of this [127].

Our meta-analysis involved a very large number of studies so even small differences, which may not be clinically significant, were rendered statistically significant. For example, the absolute difference in white blood cell count associated with mortality was 2.38 , which would not cause alarm to most clinicians. Also, several laboratory values, although significant, are not routinely available in clinical practice (e.g. lymphocyte subsets or interleukin values).

\section{Limitations}

Our meta-analysis has some limitations. There is always a risk of missing potentially germane articles, but we attempted to combat this by using a pre-specified protocol, searching multiple databases, using two independent reviewers, and searching other systematic reviews for references. There was also a very high rate of no response to email inquiries of authors for data, which could introduce bias. All of the included studies were observational, and there was, in general, a moderate risk of bias within the studies. Our process of assessing quality with two authors was not blinded, so there, again, could be bias in the assessment of quality. There also was a significant amount of heterogeneity, which can be expected when such a large number of studies is analyzed but also raises questions as to whether there are subsets of patients in whom specific laboratory values might be more or less accurate.

\section{Conclusion}

Our meta-analysis identified multiple laboratory values associated with mortality in COVID-19, but was limited by heterogeneity. Many of these have been described previously: Lymphopenia, thrombocytopenia, leukocytosis, elevated D-Dimer, ferritinemia, elevated LDH, elevated liver enzymes, and cardiac injury. Clinicians can use this information to help predict which patients are most at risk for adverse outcomes with COVID-19 and how best to allocate limited healthcare resources.

\section{Financial Support}

This research did not receive any specific grant from funding agencies in the public, commercial, or not-for-profit sectors.

\section{Conflict of Interest}

To the best of our knowledge, the authors have no conflicts of interest, financial or other, to declare regarding this manuscript.

\section{References}

1. Wu Z, McGoogan JM (2020) Characteristics of and important lessons from the Coronavirus Disease 2019 (COVID-19) outbreak in China: Summary of a report of 72314 cases from the Chinese Center for Disease Control and Prevention. JAMA 323: 12391242.

2. Mizumoto K, Chowell G (2020) Estimating risk for death from 2019 novel coronavirus disease, China, January-February 2020. Emerg Infect Dis 26: 1251-1256.

3. Verity R, Okell LC, Dorigatti I, et al. (2020) Estimates of the severity of coronavirus disease 2019: A model-based analysis. Lancet Infect Dis 20: 669-677.

4. Ñamendys SSA (2020) Respiratory support for patients with COVID-19 infection. Lancet Respir Med 8: e18.

5. Bhatraju PK, Ghassemieh BJ, Nichols M, et al. (2020) Covid-19 in critically ill patients in the seattle region - case series. $\mathrm{N}$ Engl J Med 382: 2012-2022.

6. (2020) Field briefing: Diamond princess COVID-19 cases, 20 Feb update. National Institute of Infectious Diseases, Japan. 
7. Bemtgen X, Krüger K, Supady A, et al. (2020) First successful treatment of coronavirus disease 2019 induced refractory cardiogenic plus vasoplegic shock by combination of percutaneous ventricular assist device and extracorporeal membrane oxygenation: A case report. ASAIO J 66: 607-609.

8. Petrilli CM, Jones SA, Yang J, et al. (2020) Factors associated with hospital admission and critical illness among 5279 people with coronavirus disease 2019 in New York City: Prospective cohort study. BMJ 369: m1966.

9. Ejaz H, Alsrhani A, Zafar A, et al. (2020) COVID-19 and comorbidities: Deleterious impact on infected patients. J Infect Public Health 13: 1833-1839.

10. Henry BM, de Oliveira MHS, Benoit S, et al. (2020) Hematologic, biochemical and immune biomarker abnormalities associated with severe illness and mortality in coronavirus disease 2019 (COVID-19): A meta-analysis. Clin Chem Lab Med 58: 1021-1028.

11. Zhou F, Yu T, Du R, et al. (2020) Clinical course and risk factors for mortality of adult inpatients with COVID-19 in Wuhan, China: A retrospective cohort study. Lancet 395: P1054-P1062.

12. Zhang L, Yan X, Fan Q, et al. (2020) D-dimer levels on admission to predict in-hospital mortality in patients with Covid-19. J Thromb Haemost 18: 1324-1329.

13. Connors JM, Levy JH (2020) COVID-19 and its implications for thrombosis and anticoagulation. Blood 135: 2033-2040.

14. Shi S, Qin M, Shen B, et al. (2020) Association of cardiac injury with mortality in hospitalized patients with COVID-19 in Wuhan, China. JAMA Cardiol 5: 802-810.

15. Guo T, Fan Y, Chen M, et al. (2020) Cardiovascular implications of fatal outcomes of patients with coronavirus disease 2019 (COVID-19). JAMA Cardiol 5: 811-818.

16. Liberati A, Altman DG, Tetzlaff J, et al. (2009) The PRISMA statement for reporting systematic reviews and meta-analyses of studies that evaluate healthcare interventions: Explanation and elaboration. BMJ 339: b2700.

17. Hayden JA, van der Windt DA, Cartwright JL, et al. (2013) Assessing bias in studies of prognostic factors. Ann Intern Med 158: 280-286.

18. Higgins JPT, Green S (2011) Cochrane handbook for systematic reviews of interventions version 5.1.0. The cochrane collaboration.

19. Wan X, Wang W, Liu J, et al. (2014) Estimating the sample mean and standard deviation from the sample size, median, range and/or interquartile range. BMC Med Res Methodol 14: 135.

20. Hozo SP, Djulbegovic B, Hozo I (2005) Estimating the mean and variance from the median, range, and the size of a sample. BMC Med Res Methodol 5: 13.

21. Chinn S (2000) A simple method for converting an odds ratio to effect size for use in meta-analysis. Stat Med 19: 3127-3131.

22. Al-Samkari H, Karp LRS, Dzik WH, et al. (2020) COVID-19 and coagulation: Bleeding and thrombotic manifestations of SARSCoV-2 infection. Blood 136: 489-500.

23. Aries JA, Davies JK, Auer RL, et al. (2020) Clinical outcome of coronavirus disease 2019 in haemato-oncology patients. Br J Haematol 190: e64-e67.

24. Bai T, Tu S, Wei Y, et al. (2020) Clinical and laboratory factors predicting the prognosis of patients with COVID-19: An analysis of 127 patients in Wuhan, China.
25. Benelli G, Buscarini E, Canetta C, et al. (2020) SARS-COV-2 comorbidity network and outcome in hospitalized patients in Crema, Italy. MedRxiv.

26. Bode B, Garrett V, Messler J, et al. (2020) Glycemic characteristics and clinical outcomes of COVID-19 patients hospitalized in the United States. J Diabetes Sci Technol 14: 813-821.

27. Bolondi G, Russo E, Gamberini E, et al. (2020) Iron metabolism and lymphocyte characterisation during Covid-19 infection in ICU patients: An observational cohort study. World J Emerg Surg 15: 41.

28. Brill S, Jarvis H, Ozcan E, et al. (2020) COVID-19: A retrospective cohort study with focus on the over-80s and hospital-on set disease. BMC Med 18: 194.

29. Cao J, Tu WJ, Cheng W, et al. (2020) Clinical features and shortterm outcomes of 102 patients with Coronavirus Disease 2019 in Wuhan, China. Clin Infect Dis 71: 748-755.

30. Caraballo C, McCullough M, Fuery M, et al. (2020) COVID-19 infections and outcomes in a live registry of heart failure patients across an integrated health care system. PLoS One 15: e0238829.

31. Cheng $Y$, Luo R, Wang K, et al. (2020) Kidney disease is associated with in-hospital death of patients with COVID-19. Kidney Int 97: 829-838.

32. Chen F, Sun W, Sun S, et al. (2020) Clinical characteristics and risk factors for mortality among inpatients with COVID-19 in Wuhan, China. Clin Transl Med 10: e40.

33. Chen T, Wu D, Chen H, et al. (2020) Clinical characteristics of 113 deceased patients with coronavirus disease 2019: Retrospective study. BMJ 368: m1091.

34. Ciceri F, Castagna A, Rovere QP, et al. (2020) Early predictors of clinical outcomes of COVID-19 outbreak in Milan, Italy. Clin Immunol 217: 108509.

35. Covino M, De Matteis G, Santoro M, et al. (2020) Clinical characteristics and prognostic factors in COVID-19 patients aged $\geq$ 80 years. Geriatr Gerontol Int 20: 704-708.

36. Cummings MJ, Baldwin MR, Abrams D, et al. (2020) Epidemiology, clinical course, and outcomes of critically ill adults with COVID-19 in New York City: A prospective cohort study. Lancet 395: $1763-1770$.

37. Del Valle DM, Kim SS, Huang $H$, et al. (2020) An inflammatory cytokine signature predicts COVID-19 severity and survival. Nat Med 26: 1636-1643.

38. Deng Y, Liu W, Liu K, et al. (2020) Clinical characteristics of fatal and recovered cases of coronavirus disease 2019 in Wuhan, China: A retrospective study. Chin Med J 133: 1261-1267.

39. De Smet R, Mellaerts B, Vandewinckele H, et al. (2020) Frailty and mortality in hospitalized older adults with COVID-19: Retrospective observational study. J Am Med Dir Assoc 21: 928.e1932.e1.

40. Du RH, Liang LR, Yang CQ, et al. (2020) Predictors of mortality for patients with COVID-19 pneumonia caused by SARS-CoV-2: A prospective cohort study. Eur Respir J 55: 2000524.

41. Du X, Liu Y, Chen J, et al. (2020) Comparison of the clinical implications among two different nutritional indices in hospitalized patients with COVID-19. MedRxiv.

42. Fan J, Wang H, Ye G, et al. (2020) Letter to the editor: Low-density lipoprotein is a potential predictor of poor prognosis in patients with coronavirus disease 2019. Metabolism 107: 154243. 
Citation: Davis J, Geffe S, Hana G, et al. (2020) Laboratory Markers and Mortality in Novel Coronavirus Disease 2019 (COVID-19): A Systematic Review and Meta-Analysis. Sch J Emerg Med Crit Care 4(1):106-120

43. Fei J, Fu L, Li Y, et al. (2020) Reduction of lymphocyte at early stage elevates severity and death risk of COVID-19 patients: A hospital-based case-cohort study. MedRxiv.

44. Foy BH, Carlson JCT, Reinertsen E, et al. (2020) Elevated RDW is associated with increased mortality risk in COVID-19. MedRxiv.

45. Fu L, Fei J, Xiang HX, et al. (2020) Analysis of death risk factors among 200 COVID-19 patients in Wuhan, China: A hospital-based case-cohort study.

46. Gaetano A, Ferrari A, Fontana F, et al. (2020) Hypokalemia in patients with COVID-19. MedRxiv.

47. Gan J, Li J, Li S, et al. (2020) Leucocyte subsets effectively predict the clinical outcome of patients with COVID-19 pneumonia: A retrospective case-control study. Front Public Health 8: 299.

48. Gao L, Jiang D, Wen XS, et al. (2020) Prognostic value of NT-proBNP in patients with severe COVID-19. Respir Res 21: 83.

49. Giacomelli A, Ridolfo AL, Milazzo L, et al. (2020) 30-day mortality in patients hospitalized with COVID-19 during the first wave of the Italian epidemic: A prospective cohort study. Pharmacol Res 158: 104931.

50. Goicoechea M, Sánchez Cámara LA, Macías N, et al. (2020) COVID-19: Clinical course and outcomes of 36 hemodialysis patients in Spain. Kidney Int 98: 27-34.

51. Gozalbo RR, Gimenez E, Latorre V, et al. (2020) SARS-CoV-2 antibodies, serum inflammatory biomarkers and clinical severity of hospitalized COVID-19 patients. J Clin Virol 131: 104611.

52. Garibaldi BT, Fiksel J, Muschelli J, et al. (2020) Patient trajectories and risk factors for severe outcomes among persons hospitalized for COVID-19 in the Maryland/DC region. MedRxiv.

53. Grifoni E, Valoriani A, Cei F, et al. (2020) Interleukin-6 as prognosticator in patients with COVID-19. J Infect 81: 452-482.

54. He W, Chen L, Chen L, et al. (2020) Epidemiologic and clinical characteristics of 2019 novel coronavirus disease diagnosed in hospital haematology wards in Wuhan, China: A retrospective cohort study.

55. Hu C, Liu Z, Jiang Y, et al. (2020) Early prediction of mortality risk among severe COVID-19 patients using machine learning.

56. Kong W, Zhang J, Xu Y, et al. (2020) Letter to the editor: Fasting plasma glucose associated with mortality rate in T2DM patients with COVID-19 infection. Metabolism 108: 154255.

57. Kuno T, Takahashi M, Obata R, et al. (2020) Cardiovascular comorbidities, cardiac injury, and prognosis of COVID-19 in New York City. Am Heart J 226: 24-25.

58. Li K, Chen D, Chen S, et al. (2020) Predictors of fatality including radiographic findings in adults with COVID-19. Respir Res 21: 146.

59. Li C, Hu B, Zhang Z, et al. (2020) D-dimer triage for COVID-19. Acad Emerg Med 27: 612-613.

60. Li J, Li M, Zheng S, et al. (2020) Plasma albumin levels predict risk for nonsurvivors in critically ill patients with COVID-19. Biomark Med.

61. Li J, Long X, Luo H, et al. (2020) Clinical characteristics of deceased patients infected with SARS-CoV-2 in Wuhan, China.

62. Li X, Xu S, Yu M, et al. (2020) Risk factors for severity and mortality in adult COVID-19 inpatients in Wuhan. J Allergy Clin Immunol 146: $110-118$

63. Liu Y, Du X, Chen J, et al. (2020) Neutrophil-to-lymphocyte ratio as an independent risk factor for mortality in hospitalized patients with COVID-19. J Infect 81: e6-e12.

64. Liu Q, Fang, X, Tokuno S, et al. (2020) Prediction of the clinical outcome of COVID-19 patients using T lymphocyte subsets with 340 cases from Wuhan, China: A retrospective cohort study and a web visualization tool. MedRxiv.

65. Liu Q, Song NC, Zheng ZK, et al. (2020) Laboratory findings and a combined multifactorial approach to predict death in critically ill patients with COVID-19: A retrospective study. Epidemiol Infect 148: e129.

66. Liu Y, Sun W, Guo Y, et al. (2020) Association between platelet parameters and mortality in coronavirus disease 2019: Retrospective cohort study. Platelets 31: 490-496.

67. Lu Z, Chen M, Fan Y, et al. (2020) Clinical characteristics and risk factors for fatal outcome in patients with 2019-Coronavirus infected disease (COVID-19) in Wuhan.

68. Lu J, Hu S, Fan R, et al. (2020) ACP risk grade: A simple mortality index for patients with confirmed or suspected severe acute respiratory syndrome coronavirus 2 disease (COVID-19) during the early stage of outbreak in Wuhan, China.

69. Lu Y, Lv Q, Wu X, et al. (2020) Progression, recovery and fatality in patients with SARS-CoV-2 related pneumonia in Wuhan, China: A single-centered, retrospective, observational study.

70. Luo X, Xia H, Yang W, et al. (2020) Characteristics of patients with COVID-19 during epidemic ongoing outbreak in Wuhan, China.

71. Mitra AR, Fergusson NA, Lloyd SE, et al. (2020) Baseline characteristics and outcomes of patients with COVID-19 admitted to intensive care units in Vancouver, Canada: A case series. CMAJ 192: E694-E701.

72. Pascual GNF, Monge LI, Granero $\mathrm{Cl}$, et al. (2020) Potential biomarkers predictors of mortality in COVID-19 patients in the emergency department. Rev Esp Quimioter 33: 267-273.

73. Price HEG, Burton J, Fort D, et al. (2020) Hospitalization and mortality among black patients and White patients with Covid-19. N Engl J Med 382: 2534-2543.

74. Qi X, Liu Y, Wang J, et al. (2020) Clinical course and risk factors for mortality of COVID-19 patients with pre-existing cirrhosis: A multicentre cohort study. Gut.

75. Ruan Q, Yang K, Wang W, et al. (2020) Clinical predictors of mortality due to COVID-19 based on an analysis of data of 150 patients from Wuhan, China. Intensive Care Med 46: 846-848.

76. Sciascia S, Aprà F, Baffa A, et al. (2020) Pilot prospective open, single-arm multicentre study on off-label use of tocilizumab in patients with severe COVID-19. Clin Exp Rheumatol 38: 529-532.

77. Shahriarirad R, Khodamoradi Z, Erfani A, et al. (2020) Epidemiological and clinical features of 2019 novel coronavirus diseases (COVID-19) in the South of Iran. BMC Infect Dis 20: 427.

78. Shang J, Du R, Lu Q, et al. (2020) The treatment and outcomes of patients with COVID-19 in Hubei, China: A multicentered, retrospective, observational study.

79. Sota MA, Marfil GBA, Martinez RE, et al. (2020) The LOWHARM score for predicting mortality in patients diagnosed with COVID-19: A multicentric validation study. MedRxiv.

80. Sun X, Wang J, Liu Z, et al. (2020) Characteristics of patients with COVID-19 pneumonia admitted to the intensive care unit and predictors of mortality in Wuhan, China: A single-centered retrospective cohort study. 
Citation: Davis J, Geffe S, Hana G, et al. (2020) Laboratory Markers and Mortality in Novel Coronavirus Disease 2019 (COVID-19): A Systematic Review and Meta-Analysis. Sch J Emerg Med Crit Care 4(1):106-120

81. Tang N, Bai H, Chen X, et al. (2020) Anticoagulant treatment is associated with decreased mortality in severe coronavirus disease 2019 patients with coagulopathy. J Thromb Haemost 18: 1094-1099.

82. Tang N, Li D, Wang X, et al. (2020) Abnormal coagulation parameters are associated with poor prognosis in patients with novel coronavirus pneumonia. J Thromb Haemost 18: 844-847.

83. Tomlins J, Hamilton F, Gunning S, et al. (2020) Clinical features of 95 sequential hospitalised patients with novel coronavirus 2019 disease (COVID-19), the first UK cohort. J Infect 81: e59-e61.

84. Tu WJ, Cao J, Yu L, et al. (2020) Clinicolaboratory study of 25 fatal cases of COVID-19 in Wuhan. Intensive Care Med 46: 1117-1120.

85. Wang Z, Li H, Li J, et al. (2020) Elevated serum IgM levels indicate poor outcome in patients with coronavirus disease 2019 pneumonia: A retrospective case-control study. MedRxiv.

86. Wang Y, Lu X, Li Y, et al. (2020) Clinical course and outcomes of 344 intensive care patients with COVID-19. Am J Respir Crit Care Med 201: 1430-1434.

87. Wang S, Sheng Y, Tu J, et al. (2020) Association between peripheral lymphocyte count and the mortality risk of COVID.

88. Wang W, Sun $Q$, Bao $Y$, et al. (2020) Analysis of risk factors for the thromboembolic events from 88 patients with COVID-19 pneumonia in Wuhan, China: A retrospective report.

89. Wang B, Van Oekelen O, Mouhieddine TH, et al. (2020) A tertiary center experience of multiple myeloma patients with COVID-19: Lessons learned and the path forward. J Hematol Oncol 13: 94.

90. Wang K, Zuo P, Liu Y, et al. (2020) Clinical and laboratory predictors of in-hospital mortality in patients with COVID-19: A cohort study in Wuhan, China. Clin Infect Dis 71: 2079-2088.

91. Webb GJ, Moon AM, Barnes E, et al. (2020) Determining risk factors for mortality in liver transplant patients with COVID-19. Lancet Gastroenterol Hepatol 5: 643-644.

92. Wen C, Yali Q, Zirui G, et al. (2020) Prevalence of acute kidney injury in severe and critical COVID-19 patients in Wuhan, China.

93. Wu C, Chen X, Cai Y, et al. (2020) Risk factors associated with acute respiratory distress syndrome and death in patients with Coronavirus Disease 2019 pneumonia in Wuhan, China. JAMA Intern Med 180: 934-943.

94. Wu C, Hu X, Song J, et al. (2020) Heart injury signs are associated with higher and earlier mortality in coronavirus disease 2019 (COVID-19). MedRxiv.

95. Xie $Y$, Chen S, Wang X, et al. (2020) Early diagnosis and clinical significance of acute cardiac injury - Under the cceberg: A retrospective cohort study of 619 non-critically ill hospitalized COVID-19 pneumonia patients. MedRxiv.

96. Xu B, Fan CY, Wang AL, et al. (2020) Suppressed T cell-mediated immunity in patients with COVID-19: A clinical retrospective study in Wuhan, China. J Infect 81: e51-e60.

97. Xu PP, Tian RH, Luo S, et al. (2020) Risk factors for adverse clinical outcomes with COVID-19 in China: A multicenter, retrospective, observational study. Theranostics 10: 6372-6383.

98. Xu J, Yang X, Yang L, et al. (2020) Clinical course and predictors of 60-day mortality in 239 critically ill patients with COVID-19: A multicenter retrospective study from Wuhan, China. Crit Care 24: 394.

99. Yan Y, Yang Y, Wang F, et al. (2020) Clinical characteristics and outcomes of patients with severe covid-19 with diabetes. BMJ Open Diabetes Res Care 8: e001343.

100. Yang JK, Jin JM, Liu S, et al. (2020) New onset COVID-19-related diabetes: 1 an indicator of mortality. MedRxiv.

101. Yang K, Sheng Y, Huang C, et al. (2020) Clinical characteristics, outcomes, and risk factors for mortality in patients with cancer and COVID-19 in Hubei, China: A multicentre, retrospective, cohort study. Lancet Oncol 21: 904-913.

102. Yang $X$, Yang $Q$, Wang $Y$, et al. (2020) Thrombocytopenia and its association with mortality in patients with COVID-19. J Thromb Haemost 18: 1469-1472.

103. Yang X, Yu Y, Xu J, et al. (2020) Clinical course and outcomes of critically ill patients with SARS-CoV-2 pneumonia in Wuhan, China: A single-centered, retrospective, observational study. Lancet Respir Med 8: P475-P481.

104. Yin $Y$, Zhou S, Zhang $X$, et al. (2020) Critically ill patients with COVID-19 in China: A multicenter retrospective observational study. SSRN.

105. Zhang J, Ding D, Cao C, et al. (2020) Myocardial characteristics as the prognosis for COVID-19 patients. MedRxiv.

106. Zhang S, Guo M, Duan L, et al. (2020) Development and validation of a risk factor-based system to predict short-term survival in adult hospitalized patients with COVID-19: A multicenter, retrospective, cohort study. Crit Care 24: 438.

107. Zhang G, Hu C, Luo L, et al. (2020) Clinical features and shortterm outcomes of 221 patients with COVID-19 in Wuhan, China. J Clin Virol 127: 104364.

108. Zhang Y, Li H, Zhang J, et al. (2020) The clinical characteristics and outcomes of patients with diabetes and secondary hyperglycaemia with coronavirus disease 2019: A single-centre, retrospective, observational study in Wuhan. Diabetes ObesMetab 22: 1443-1454.

109. Zhang L, Sun W, Chen L, et al. (2020) Clinical features and a simple model for predicting the mortality of coronavirus disease 2019 patients on admission. SSRN.

110. Zhang F, Yang D, Li J, et al. (2020) Myocardial injury is associated with in-hospital mortality of confirmed or suspected COVID-19 in Wuhan, China: A single center retrospective cohort study. Med Rxiv.

111. Zhang S, Zhao J, Wu Z, et al. (2020) Potential predictors for disease progression and medication evaluation of 2019 novel coronavirus-infected pneumonia in Wuhan, China.

112. Zhu Q, Zhao S, Lai $X$, et al. (2020) Dose-response association between risk actors and incidence of COVID-19 in 325 hospitalized patients: A multicenter retrospective cohort study.

113. Zou X, Li S, Fang M, et al. (2020) Acute physiology and chronic health evaluation II Score as a predictor of hospital mortality in patients of Coronavirus Disease 2019. Crit Care Med 48: e657-e665.

114. Carpenter CR, Mudd PA, West CP, et al. (2020) Diagnosing COVID-19 in the emergency department: A scoping review of clinical examinations, laboratory tests, imaging accuracy, and biases. Acad Emerg Med 27: 653-670.

115. Jiang J, Liu R, Yu X, et al. (2019) The neutrophil-lymphocyte count ratio as a diagnostic marker for bacteraemia: A systematic review and meta-analysis. Am J Emerg Med 37: 1482-1489.

116. Cho S, Jung S, Lee K, et al. (2018) Neutrophil to lymphocyte 
ratio and platelet to lymphocyte ratio can predict the severity of gallstone pancreatitis. BMC Gastroenterol 18: 18.

117. Han C, Zeng J, Lin R, et al. (2017) The utility of neutrophil to lymphocyte ratio and fluid sequestration as an early predictor of severe acute pancreatitis. Sci Rep 7: 10704.

118. Kayrak $M$, Erdoğan $H$, Solak $Y$, et al. (2014) Prognostic value of neutrophil to lymphocyte ratio in patients with acute pulmonary embolism: A restrospective study. Heart Lung Circ 23 56-62.

119. Zou F, Qian Z, Wang Y, et al. (2020) Cardiac injury and COVID-19: A systematic review and meta-analysis. CJC Open 2: 386-394.

120. Siripanthong B, Nazarian S, Muser D, et al. (2020) Recognizing COVID-19-related myocarditis: The possible pathophysiology and proposed guideline for diagnosis and management. Heart Rhythm 17: 1463-1471.

121. Tsang KW, Ho PL, Ooi GC, et al. (2003) A cluster of cases of severe acute respiratory syndrome in Hong Kong. N Engl J Med 348: 1977-1985.
122. Giannini EG, Testa R, Savarino V (2005) Liver enzyme alteration: A guide for clinicians. CMAJ 172: 367-379.

123. Pratt DS, Kaplan MM (2000) Evaluation of abnormal liver-enzyme results in asymptomatic patients. $N$ Engl J Med 342: $1266-1271$.

124. Schaefer EAK, Arvind A, Bloom PP, et al. (2020) Interrelationship between coronavirus infection and liver disease. Clin Liver Dis (Hoboken) 15: 175-180.

125. Li G (2020) Aspartate aminotransferase: A prognostic marker rather than a specific liver injury marker in COVID-19. J Infect 81: e155.

126. Freund $Y$, Drogrey M, Miró Ò, et al. (2020) Association between pulmonary embolism and COVID-19 in emergency department patients undergoing computed tomography pulmonary angiogram: The PEPCOV international retrospective study. Acad Emerg Med 27: 811-820.

127. Klok FA, Kruip MJHA, van der Meer NJM, et al. (2020) Incidence of thrombotic complications in critically ill ICU patients with COVID-19. Thromb Res 191: 145-147. 